\title{
Effects of smoking cessation on biological monitoring markers in urine
}

Yuya Kawasaki ${ }^{1}$, Yun-Shan Li ${ }^{1}$, Yuko Ootsuyama ${ }^{1}$, Kazuhiko Nagata ${ }^{2}$, Hiroshi Yamato ${ }^{3}$ and Kazuaki Kawai ${ }^{1,4^{*}}$ (D)

\begin{abstract}
Introduction: Urinary nicotine and cotinine levels are often measured as biomarkers for tobacco smoke exposure. However, these biomarkers are not appropriate to evaluate the effects of quitting smoking for several days, because of their short half-lives. In this study, we focused on the changes in the urinary 4-(methylnitrosamino)-1-(3-pyridyl)1-butanol (NNAL) levels of 55 patients in a smoking cessation program, because of the long half-life. At the same time, urinary 7-methylguanine ( $\mathrm{m}^{7} \mathrm{Gua}$ ) and 8-hydroxy-2'-deoxyguanosine (8-OHdG), as DNA damage markers of cigarette smoking, were also measured.
\end{abstract}

Results: In the subjects who completed the quit-smoking program (18 subjects out of 55), the urinary nicotine and cotinine levels decreased to 1.7 and $0.2 \%$ at 8 weeks after the first visit to the clinic. By contrast, the NNAL levels decreased to $12.3 \%$ at 8 weeks after quitting smoking. During the same period, the urinary $\mathrm{m}^{7}$ Gua levels significantly decreased, from $27.32 \mu \mathrm{g} / \mathrm{mg}$ creatinine to $14.17 \mu \mathrm{g} / \mathrm{mg}$ creatinine by the elimination of subjects who showed increased levels of NNAL during the smoking cessation program. The 8-OHdG levels were also reduced within the same period, but were not significantly different. From the all data analysis, the urinary levels of cotinine and NNAL positively correlated with the level of $\mathrm{m}^{7}$ Gua.

Conclusions: NNAL may be an appropriate exposure marker for evaluating the smoking status of patients in a smoking cessation program. The urinary cotinine and NNAL levels positively correlated with the $\mathrm{m}^{7}$ Gua levels.

Keywords: Nicotine, Cotinine, 4-(methylnitrosamino)-1-(3-pyridyl)-1-butanol (NNAL), 7-methylguanine ( $\left.m^{7} \mathrm{Gua}\right), 8$ hydroxy-2'-deoxyguanosine (8-OHdG), Smoking cessation

\section{Introduction}

Tobacco smoke contains more than 5000 chemicals and over 70 types of carcinogens [1, 2]. Smoking has been established as a risk factor for many common cancers [3]. The percentage of smokers is decreasing each year in Japan (from $24.2 \%$ in 2006 to $17.8 \%$ in 2018); however, it still remains high, especially among men $(29.0 \%$ in men vs. $8.1 \%$ in women) [4]. Smoking cessation is one

\footnotetext{
* Correspondence: kkawai@med.uoeh-u.ac.jp

${ }^{1}$ Department of Environmental Oncology, Institute of Industrial Ecological Sciences, University of Occupational and Environmental Health, Japan, 1-1 Iseigaoka, Yahatanishi-ku, Kitakyushu, Fukuoka 807-8555, Japan ${ }^{4}$ Center for Stress-related Disease Control and Prevention, University of Occupational and Environmental Health, Japan, 1-1 Iseigaoka, Yahatanishi-ku, Kitakyushu, Fukuoka 807-8555, Japan

Full list of author information is available at the end of the article
}

of the most effective interventions to prevent cancer. At smoking cessation programs in hospitals and clinics, the abstinence status is usually biochemically confirmed by an expiratory carbon monoxide (CO) concentration below $9 \mathrm{ppm}$. However, due to the short half-life of $\mathrm{CO}$ ( $2 \mathrm{~h}$ ), many people who smoked over $24 \mathrm{~h}$ before the test could be misclassified as quitters [5]. In addition to CO, biochemical verification of tobacco abstinence can be obtained by measuring the cotinine levels in urine, plasma and saliva. Cotinine is the main metabolite of nicotine and has a longer half-life $(18 \mathrm{~h})$ than $\mathrm{CO}$ and nicotine (2h) [6]. In measurements of tobacco use, cotinine has relatively high sensitivity and specificity, as compared to $\mathrm{CO}$ levels. Therefore, it is a reliable indicator of recent nicotine intake [7]. However, for patients 
undergoing nicotine replacement therapy (NRT) using nicotine gum and nicotine patches, cotinine cannot be used as an indicator of smoking cessation because nicotine and cotinine are present at the same levels as smokers [8-12]. On the other hand, 4-(methylnitrosamino)-1-(3-pyridyl)-1-butanol (NNAL) in urine has been reported as an exposure indicator that is not affected by NRT [13, 14]. NNAL is a tobacco-specific nitrosamine and a metabolite of the carcinogenic 4-(methylnitrosamino)-1-(3-pyridyl)-1-butanone (NNK) in humans [3]. Many studies have investigated the urinary NNAL levels in smokers and secondhand smokers $[15,16]$. As urine contains quantitatively significant NNK metabolites, the NNAL levels in urine are critically useful in studies of human exposure to tobacco smoke. Urinary NNAL has a much longer half-life (10-40 days) than urinary cotinine and can be detected even a few weeks after smoking [6]. Therefore, NNAL is a possible candidate for an indicator of quitting smoking. However, only a few studies have used urinary NNAL as an indicator of smoking cessation in clinical settings.

Tobacco smoke contains many carcinogens that can lead to DNA methylation and oxidation. A metabolite of NNK and NNAL, methanediazonium ion, reacts with DNA to form methyl DNA base adducts, including 7methylguanine ( $\mathrm{m}^{7} \mathrm{Gua}$ ) and $\mathrm{O}^{6}$-methyl deoxyguanine [17]. $\mathrm{m}^{7} \mathrm{Gua}$ is removed from DNA by a glycosylase to produce an apurinic site [18]. As the result, $\mathrm{m}^{7}$ Gua is excreted into the urine. The apurinic site is a frequent cause of mutations in mammalian cells $[19,20]$. Current smokers had higher $\mathrm{m}^{7} \mathrm{Gua}$ levels in their lung DNA [21]. A correlation between urinary $\mathrm{m}^{7}$ Gua levels and urinary NNAL levels has been reported [22].

Oxidative damage of DNA by reactive oxygen species leads to the production of 8-hydroxy-2'-deoxyguanosine (8-OHdG), a specific biomarker of oxidative stress [23-25]. Several studies reported that urinary 8-OHdG levels [26-28] and salivary 8-hydroxyguanine levels [29, 30] correlated with smoking. Cao et al. [31] reported that the levels of 8-OHdG in bronchoalveolar lavage fluid were associated with the Tumor Node Metastasis stage, indicating that oxidative DNA damage is a marker for the development of lung cancer.

The purpose of this study is to investigate the reductions of cigarette smoking exposure markers (nicotine, cotinine and NNAL) and DNA damage markers $\left(\mathrm{m}^{7}\right.$ Gua and $8-\mathrm{OHdG}$ ) in patients participating in a smoking cessation program.

\section{Materials and methods}

\section{Subjects and urine sample collection}

A total of 55 subjects (36 male and 19 female, ages 2568) from a smoking cessation clinic in Japan participated in the study. After excluding samples because of only a single visit or the use of only heated tobacco products, a total of 42 subjects ( 26 male and 16 female) were selected for the analysis (Table 1).

Subjects visited the clinic 2 to 5 times during the 12week treatment period, and urine samples were collected at the first visit and at weeks 2 and 8 after quitting smoking. The number of subjects who participated up to the second visit ( 2 weeks) was 42 (Group 1; 26 male and 16 female). The number of subjects who participated up to the third visit (8 weeks) was 18 (Group 2; 11 male and 7 female). At each clinic visit, $10 \mathrm{~mL}$ urine samples were collected in polypropylene centrifuge tubes and stored at $-20{ }^{\circ} \mathrm{C}$ until analysis. The study protocol was approved by the Ethics Committee of Medicine and Medical Care, University of Occupational and Environmental Health, Japan.

\section{Chemicals}

(-)-Nicotine ( $\geq 98 \%),(-)$-cotinine ( $\geq 98 \%)$, and Type H-1 $\beta$ glucuronidase $(208,400$ units/g solid) were obtained from Sigma Aldrich Inc. (St. Louis, MO). Isolute SLE+ column cartridges were purchased from Biotage (Uppsala, Sweden). Chloroform ( $\geq 99.7 \%)$ and acetic acid $(\geq 99.7 \%)$ were purchased from FUJIFILM Wako Pure Chemicals Co., Inc. (Osaka, Japan). Acetonitrile ( $\geq 99.8 \%), 1 \mathrm{~mol} / \mathrm{L}$ ammonium acetate solution (LC/MS grade) and distilled water (LC/MS grade) were purchased from Kanto Chemical Co., Inc. (Tokyo, Japan). NNAL $(100 \mu \mathrm{g} / \mathrm{mL}$ in acetonitrile), DLmethyl- $\mathrm{D}_{3}$-cotinine $\left(100 \mu \mathrm{g} / \mathrm{mL}\right.$ in acetonitrile), and $1,2^{\prime}$, $3^{\prime}, 4^{\prime}, 5^{\prime}, 6^{\prime}-{ }^{13} \mathrm{C}_{6}$-NNAL $(100 \mu \mathrm{g} / \mathrm{mL}$ in acetonitrile) were obtained from Cambridge Isotope Laboratories, Inc. (Tewksbury, MA). The stock solutions (each $100 \mu \mathrm{g} / \mathrm{mL}$ ) of nicotine, cotinine, and NNAL were prepared in acetonitrile. DL-methyl-D ${ }_{3}$-cotinine $(10 \mu \mathrm{g} / \mathrm{mL})$ and ${ }^{13} \mathrm{C}_{6}$-NNAL (20 $\mathrm{ng} / \mathrm{mL}$ ) stock solutions were also prepared in acetonitrile. The working solutions were prepared using serial dilutions of the stock solutions with a $10 \%(\mathrm{v} / \mathrm{v})$ acetonitrile solution containing $10 \mathrm{mM}$ ammonium acetate.

\section{Sample preparation}

Frozen urine samples were thawed at room temperature. Urine $(500 \mu \mathrm{L})$ was mixed with $500 \mu \mathrm{L}$ of acetate buffer ( $50 \mathrm{mM}, \mathrm{pH} 4.0$ ), followed by the addition of $2 \mu \mathrm{L}$ of DLmethyl- $\mathrm{D}_{3}$-cotinine and ${ }^{13} \mathrm{C}_{6}$-NNAL stock solutions as internal standards. $\beta$-Glucuronidase $(1000 \mathrm{U} / 500 \mu \mathrm{L}$ of urine) was then added and the solution was incubated at $37^{\circ} \mathrm{C}$ for $15 \mathrm{~h}$. The mixture was loaded onto Isolute

Table 1 Participants in this study

\begin{tabular}{llll}
\hline & Mean \pm SD & \\
\cline { 2 - 4 } & Male & Female & Total \\
\hline Ages (years) & $44.6 \pm 12.7$ & $42.8 \pm 10.3$ & $43.9 \pm 11.8$ \\
$\mathrm{n}$ & 26 & 16 & 42 \\
\hline
\end{tabular}


SLE + column cartridges (Biotage) and allowed to adsorb on the diatomaceous earth supported material for 10 min, followed by elution with $6 \mathrm{~mL}$ of chloroform. The extract was evaporated to dryness at $40{ }^{\circ} \mathrm{C}$ under a continuous flow of nitrogen. The residue was dissolved in $200 \mu \mathrm{L}$ of a $10 \%(\mathrm{v} / \mathrm{v})$ acetonitrile solution containing 10 $\mathrm{mM}$ ammonium acetate. The solution was filtered through a pretreatment filter. The filtered solution was divided into $100 \mu \mathrm{L}$ aliquots. One was diluted 5-20-fold with a $10 \%$ acetonitrile solution containing $10 \mathrm{mM}$ ammonium acetate, for the measurement of urinary nicotine and cotinine. The other was used for urinary NNAL measurement without dilution.

\section{Liquid chromatography and mass spectrometry conditions}

Analyses of urinary nicotine, cotinine and NNAL were conducted using an HPLC (UltiMate 3000, Thermo Fisher Scientific, Yokohama, Japan) coupled to a hybrid quadrupole-Orbitrap mass spectrometer (Thermo Scientific Q Exactive Focus) with heated electrospray ionization (HESI-II). The sample separation was achieved on an Acclaim $^{\text {тм }} 120 \mathrm{C} 18(2.1 \mathrm{~mm} \times 50 \mathrm{~mm}, 3 \mu \mathrm{m}$, Thermo Scientific, Sunnyvale, CA) column with a flow rate of $0.3 \mathrm{~mL} / \mathrm{min}$ and a column temperature of $30^{\circ} \mathrm{C}$. Mobile phase A was 10 $\mathrm{mM}$ ammonium formate and mobile phase $\mathrm{B}$ was acetonitrile. The following linear gradient program was used for the separation, with a total run time of $15 \mathrm{~min}$. The percentage of B solvent (acetonitrile) changed as follows: 0 min, 5\%; $8 \mathrm{~min}, 32 \%$; $8.1-11 \mathrm{~min}, 95 \%$; $11.1-15 \mathrm{~min}, 5 \%$. For measurements, the injection volumes were $2 \mu \mathrm{L}$ for nicotine and cotinine, and $5 \mu \mathrm{L}$ for NNAL. The ESI source was set to a heater temperature of $300{ }^{\circ} \mathrm{C}$ and the sheath gas and auxiliary gas pressures were set to 50 and 15 arbitrary units, respectively. The ion spray voltage was set to $2.5 \mathrm{kV}$, with a capillary temperature of $250{ }^{\circ} \mathrm{C}$, and the S-lens RF level was 40. Data were acquired in the parallel reaction monitoring (PRM) mode. In this mode, a single precursor ion $[\mathrm{M}+\mathrm{H}]^{+}$was selected in the quadrupole with an isolation width of $2.0 \mathrm{~m} / \mathrm{z}$. After fragmentation in the higher energy collisioninduced dissociation (HCD) cell, the resulting MS/MS product ions were detected in the Orbitrap detector at a resolution of 70,000. The most abundant ion was used for quantification.

\section{Calibration curves}

The calibration standards were prepared at concentrations of $10,50,100,250$, and $500 \mathrm{ng} / \mathrm{mL}$ nicotine, and 5 , 10, 50, 100, 250, and $500 \mathrm{ng} / \mathrm{mL}$ cotinine. Each standard solution was then spiked with $100 \mathrm{ng} / \mathrm{mL}$ of DL-methyl$\mathrm{D}_{3}$-cotinine. The NNAL calibration curve was generated based on concentrations of 10, 50,100, 250, and $500 \mathrm{pg} /$ $\mathrm{mL}$ and each standard solution was spiked with $200 \mathrm{pg} /$ $\mathrm{mL}$ of ${ }^{13} \mathrm{C}_{6}$-NNAL. The calculations of limit of detection
(LOD) and limit of quantification (LOQ) were applied to $3 \sigma$ and $10 \sigma$ criteria. If the value (before correction by the dilution ratio and urinary creatinine level) calculated from each calibration curve was less than the LOQ, then it was set to 0 level.

\section{Analyses of urinary 8-OHdG and $\mathrm{m}^{7} \mathrm{Gua}$}

Urinary $\mathrm{m}^{7}$ Gua and $8-\mathrm{OHdG}$ concentrations were determined by the previously described method [32]. Briefly, a human urine sample was mixed with the same volume of a dilution solution containing the ribonucleoside marker, 8-hydroxyguanosine (8-OHG). A $20 \mu \mathrm{L}$ aliquot of the diluted urine sample was injected into HPLC-1 (MCI GEL CA08F, $7 \mu \mathrm{m}, 1.5 \times 120 \mathrm{~mm}$; elution, $2 \%$ acetonitrile in $0.3 \mathrm{mM}$ sulfuric acid, $50 \mu \mathrm{L} / \mathrm{min}, 65^{\circ} \mathrm{C}$ ), via the guard column $(1.5 \times 40 \mathrm{~mm})$, and the chromatograms were recorded by a Gilson UV detector (UV/VIS155 with $0.2 \mathrm{~mm}$ light path cell). Creatinine and $\mathrm{m}^{7} \mathrm{Gua}$ were detected at 235 and $305 \mathrm{~nm}$, respectively. The 8OHdG fraction was collected, depending on the relative elution position from the peak of the added marker, 8OHG, and was automatically injected into the HPLC-2 column. The 8-OHdG fraction was fractionated by the HPLC-2 column (GL Science Inc., Inertsil ODS-3, $3 \mu \mathrm{m}$, $4.6 \times 250 \mathrm{~mm}$; elution, $10 \mathrm{mM}$ sodium phosphate buffer [pH 6.7] containing 5\% methanol and an antiseptic reagent $\left.\mathrm{MB}[100 \mu \mathrm{L} / \mathrm{L}], 1 \mathrm{~mL} / \mathrm{min}, 45^{\circ} \mathrm{C}\right)$. The 8 -OHdG was detected by a Coulochem II EC detector (ESA Inc., Chemsford, MA, USA) with a guard cell (5020) and an analytical cell (5011) (applied voltages: guard cell, 350 $\mathrm{mV}$; E1, $100 \mathrm{mV}$; E2, $300 \mathrm{mV}$ ).

\section{Statistical methods}

The values of each biomarker were compared with the median, because the data did not follow a normal distribution. Statistical analyses were performed using GraphPad Prism, version 7.04 (GraphPad Software, San Diego, CA, USA). Data were tested for normality using Shapiro-Wilk's test. Non-parametric tests were used because all variables were not normally distributed. Two-sided $p$ values less than 0.05 were considered significant.

\section{Results}

Detection sensitivity of urinary tobacco exposure markers The lower detection limits for nicotine, cotinine, and NNAL were determined to be $0.79 \mathrm{ng} / \mathrm{mL}, 0.21 \mathrm{ng} / \mathrm{mL}$, and $1.85 \mathrm{pg} / \mathrm{mL}$, respectively. The lower limits of quantification for nicotine, cotinine, and NNAL were $2.62 \mathrm{ng} /$ $\mathrm{mL}, \quad 0.71 \mathrm{ng} / \mathrm{mL}$, and $6.17 \mathrm{pg} / \mathrm{mL}$, respectively. The correlation coefficients $\left(\mathrm{r}^{2}\right)$ were $>0.99$ in all cases. Representative chromatograms of these exposure markers in urine from a smoker are shown in Fig. 1. 


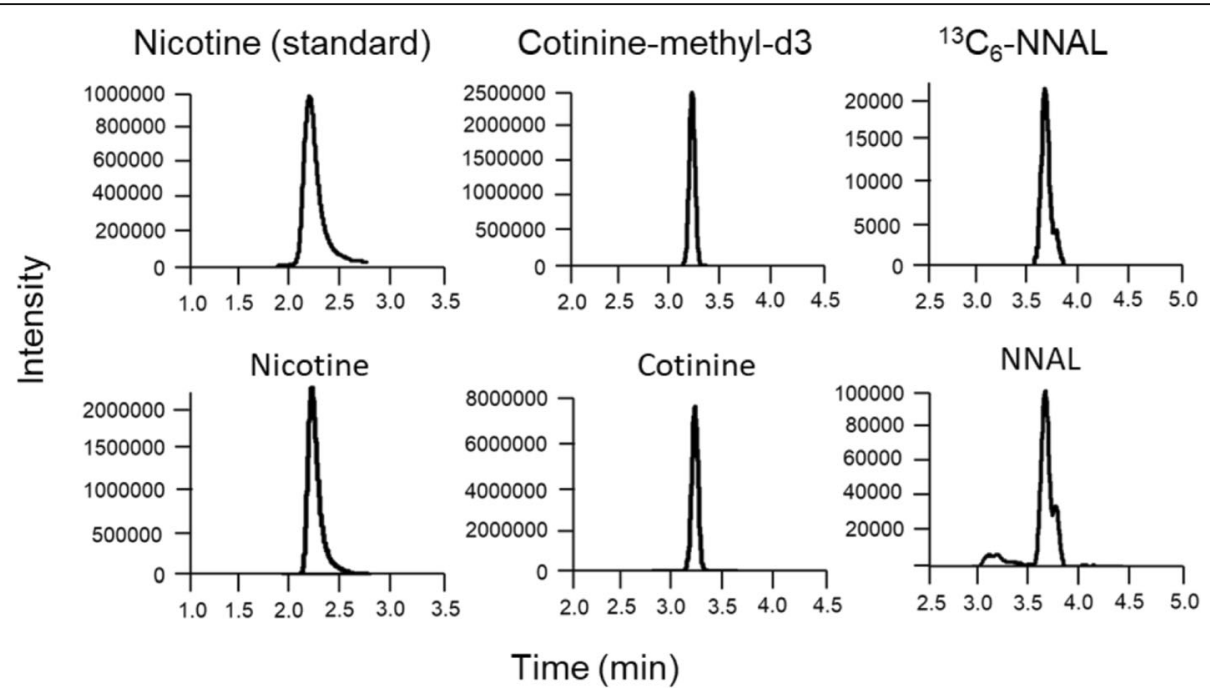

Fig. 1 Chromatograms of smoking exposure markers in urine. Upper row: authentic samples, Lower row: urine sample

Urinary biomarker levels after smoking cessation

Urinary levels of cigarette smoking markers decreased clearly with time after smoking cessation for 2 and 8 weeks (Fig. 2). Among the subjects who completed the quit-smoking program (Group 2 in Fig. 2), the median values of the urinary nicotine levels (minimum-maximum) at the initial visit to the tobacco cessation clinic, and at 2 and 8 weeks later were $477.2(36.3-2226.5) \mathrm{ng} /$ mg creatinine, 8.7 (not detected (n.d.) - 264.9) ng/mg creatinine, and $8.2(1.9-263.1) \mathrm{ng} / \mathrm{mg}$ creatinine. The urinary cotinine levels at the same times were 3006.0 (496.4-14,084.5) ng/mg creatinine, 102.7 (2.3-969.8) ng/ mg creatinine, and 6.1 (n.d. - 2803.7) ng/mg creatinine. The urinary NNAL levels were 171.7 (31.0-700.9) pg/ mg creatinine, 53.9 (10.9-151.4) pg/mg creatinine, and 21.1 (4.4-174.0) $\mathrm{pg} / \mathrm{mg}$ creatinine. The nicotine, cotinine, and NNAL levels are represented as the total of the free and glucuronidated forms. The individual changes of each biomarker are shown in Fig. 2d-f. Looking at each individual, the urinary NNAL levels of 9 subjects ( 5 subjects in Group 1 and 6 subjects in Group 2, two subjects overlapped) increased at some points during smoking cessation, as compared to the previous medical examination. Although the rates of the NNAL increases were not markedly high, in order to evaluate the effects of quitting smoking on the DNA damage markers, those subjects were eliminated from the following group analysis and monitored separately. Consequently, the DNA damage markers in urine, as the early adverse health effect markers, were analyzed separately for those 9 individuals. In the analysis excluding those subjects, the DNA damage markers in urine decreased with time after smoking cessation (Fig. 3). In the subjects who completed the smoking cessation program (Group 4 in Fig. 3), the median values (with minimum-maximum) of the urinary $\mathrm{m}^{7} \mathrm{Gua}$ levels at the initial visit to the tobacco cessation clinic, and at 2 and 8 weeks later were 27.32 (8.21-41.30) $\mu \mathrm{g} / \mathrm{mg}$ creatinine, 16.17 (6.05-58.94) $\mu \mathrm{g} / \mathrm{mg}$ creatinine, and 14.17 (6.02-47.06) $\mu \mathrm{g} / \mathrm{mg}$ creatinine. The urinary $8-\mathrm{OHdG}$ levels at the same times were 5.21 (2.61-8.60) ng/mg creatinine, 4.75 (2.85-6.87) ng/mg creatinine, and 5.09 (2.14-9.20) ng/mg creatinine, respectively. In the case of all subjects (Group 3 in Fig. 3), even discontinued subjects were included, and their urinary $\mathrm{m}^{7} \mathrm{Gua}$ and 8-OHdG levels were significantly decreased at 2 weeks. By contrast, in the group of subjects who showed increased NNAL levels at some points during the smoking cessation program, the $\mathrm{m}^{7} \mathrm{Gua}$ and 8 -OHdG levels did not coincide with the smoking cessation duration (Fig. 4).

\section{Correlation between the urinary levels of each biomarker}

All data at 0,2 , and 8 weeks from all subjects were used for the correlation analyses. Among the exposure biomarkers, the urinary levels of nicotine, cotinine and NNAL significantly correlated with each other (Table 2).

In the cases of the DNA damage biomarkers, the urinary levels of $\mathrm{m}^{7}$ Gua were weakly related to the $8-\mathrm{OHdG}$ levels. A comparison of the exposure markers with the DNA damage markers revealed that the urinary levels of cotinine and NNAL positively correlated with the level of $\mathrm{m}^{7} \mathrm{Gua}$, but not with the 8-OHdG. The nicotine levels were not correlated with the $\mathrm{m}^{7}$ Gua and 8-OHdG levels.

\section{Discussion}

In a handful of individuals, the urinary nicotine and cotinine levels remained high after two weeks of the quit-smoking program, even though the median values were low in the results for all participants (Group 1 in Fig. 2a and b). Considering the short biological half-lives of nicotine and cotinine, a reasonable explanation is that 

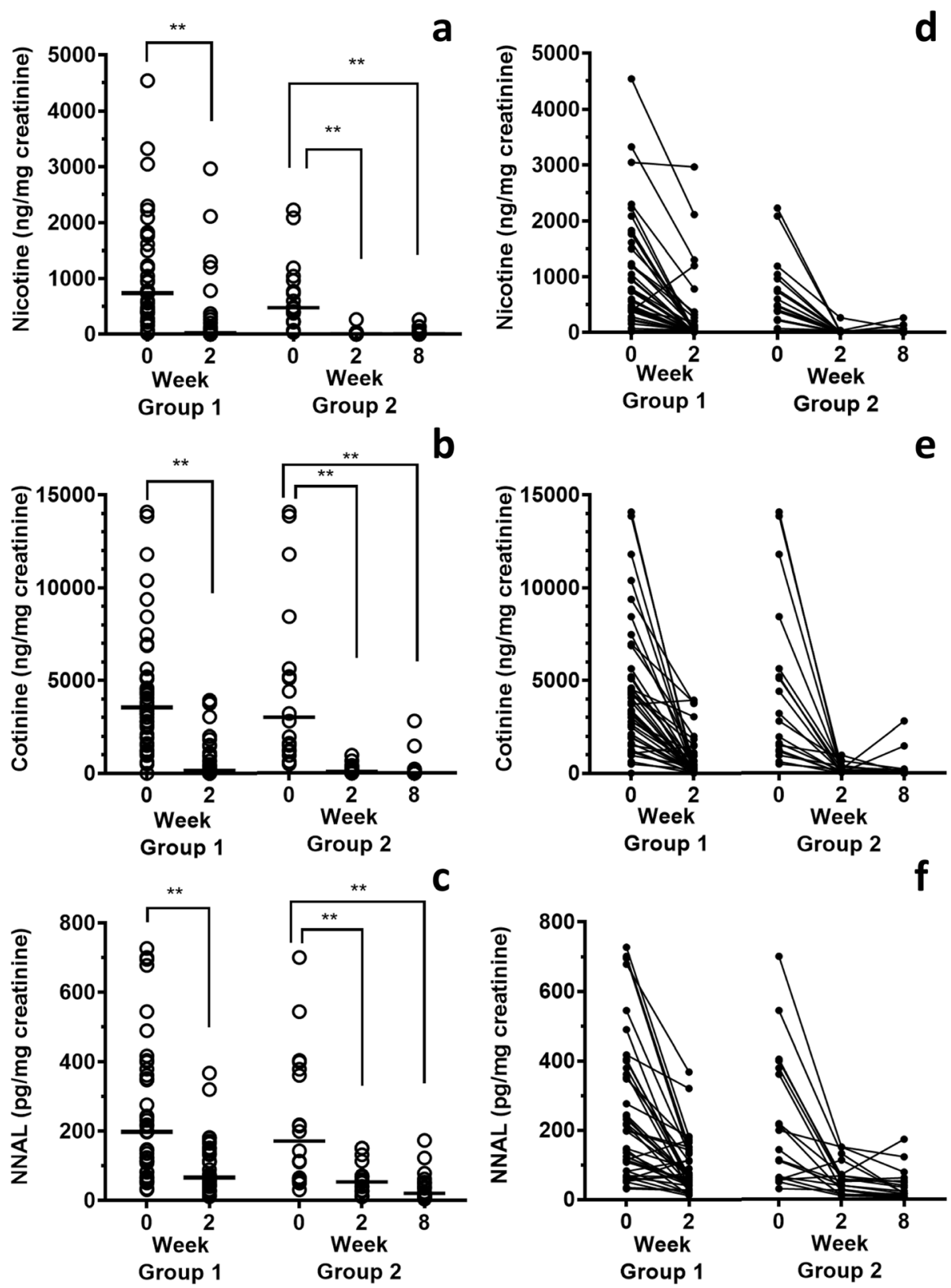

Fig. 2 Changes in urinary tobacco exposure biomarker levels by smoking cessation. Horizontal bars indicate medians. Group 1: The subjects who participated in the quit-smoking program for 2 weeks $(n=42$, Wilcoxon signed-rank test). Group 2: The subjects who completed the quit-smoking program ( $n=18$, Friedman's test followed by Dunn's multiple comparisons test). ${ }^{*} p<0.01$. Individual changes in biomarkers are indicated by the lines in $(\mathbf{d}-\mathbf{f})$

the high levels were caused by smoking before visiting the clinic. Interestingly, among the subjects who completed the quit-smoking program, no one had such high levels of nicotine and cotinine (Group 2 in Fig. 2a and b). These high levels are probably derived from some subjects who could not continue the quit smoking program and had dropped out. Among the subjects who completed the quit-smoking program (Group 2 in Fig. 2), the urinary nicotine and cotinine levels decreased to 1.8 and $3.4 \%$ after quitting smoking for 2 weeks, and then to 1.7 and $0.2 \%$ after 8 weeks, relative to the values at the beginning of the smoking cessation program. In comparison, the NNAL levels were 31.4 and $12.3 \%$ at 2 and 8 weeks. These reduction rates were slower than those in previous reports with subjects in the United States [13,33]. They may reflect racial differences in the metabolic rates of tobacco- 


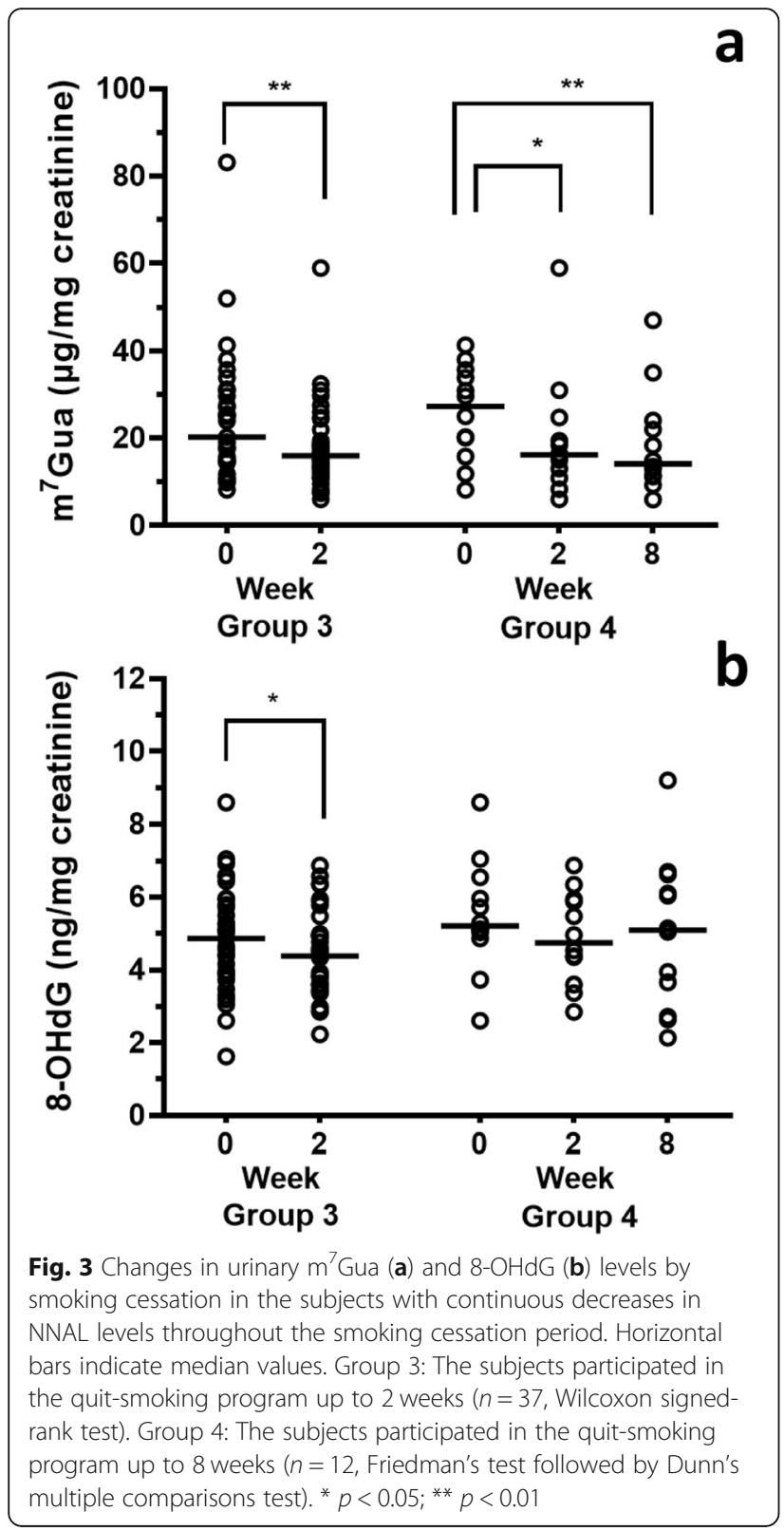

specific biomarkers. In fact, Asians reportedly had slower rates of nicotine metabolism, as compared with those of Whites and Hispanics [34].

In this study, the smoking status during the quitsmoking program was confirmed by a medical interview of each subject during their visits to the clinic. As a result, 8 subjects mentioned smoking at some point during the quit-smoking program. Among them, however, the nicotine, cotinine, and NNAL levels were increased in only 1 subject. The smoking levels of the other 7 subjects did not elicit the increases in urinary biomarker levels measured during the clinical assessment. In many cases, increased levels of nicotine, cotinine, and NNAL were observed in the subjects who described themselves
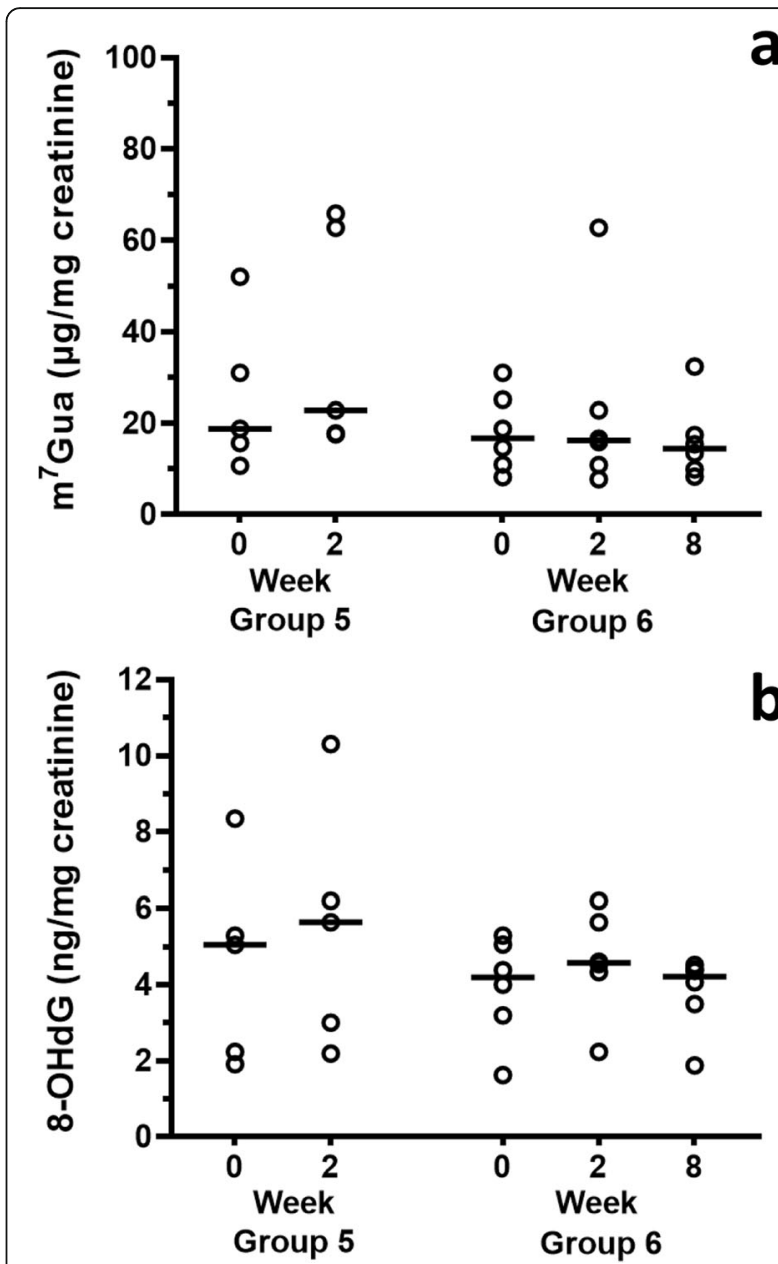

Fig. 4 Changes in urinary $m^{7}$ Gua (a) and 8-OHdG (b) levels by smoking cessation in the subjects with increased NNAL levels at some point in the smoking cessation program. Horizontal bars indicate median values. Group 5: The subjects with increased NNAL levels at 2 weeks $(n=5)$. Group 6: The subjects who participated in the quit-smoking program for up to 8 weeks and had increased NNAL levels at some point ( $n=6$, Friedman's test followed by Dunn's multiple comparisons test). There are no significant differences from baseline

Table 2 Spearman's rank correlation coefficients of associations between urinary biomarkers of tobacco exposure, $8-\mathrm{OHdG}$, and $m^{7}$ Gua

\begin{tabular}{lllll}
\hline Variable & \multicolumn{4}{l}{ Correlation coefficients } \\
\cline { 2 - 5 } & Nicotine & Cotinine & NNAL & m $^{7}$ Gua \\
\hline Cotinine & $0.80^{* *}$ & - & - & - \\
NNAL & $0.61^{* *}$ & $0.66^{* *}$ & - & - \\
$m^{7}$ Gua & 0.16 & $0.26^{* *}$ & $0.35^{* *}$ & - \\
$8-O H d G$ & 0.04 & -0.06 & -0.02 & $0.22^{*}$ \\
\hline
\end{tabular}

${ }^{*}$ indicates $p<0.05 .{ }^{* *}$ indicates $p<0.01$ 
as non-smokers. Considering that these biomarkers are specific for tobacco smoking, some subjects might have not correctly declared their smoking status. In the quitsmoking program, the subjects visited the clinic at 2 or 4 week intervals. The smoking amounts and durations were not accurately identifiable from the clinical interview. Therefore, it is important to measure the tobaccospecific urinary biomarkers.

Urinary NNAL is a specific biomarker for tobacco exposure. It is not detected in nonsmokers, unless they are exposed to secondhand smoke [15]. Benowitz et al. [35] reported that the average NNAL levels were $183 \mathrm{pg} /$ mg creatinine in the urine for 373 active smokers and $5.19 \mathrm{pg} / \mathrm{mg}$ creatinine for 228 passive smokers. In this study, the average NNAL levels of the subjects at the initial visit to the clinic were similar to those of the active smokers in the previous report. For patients who visit the hospitals or clinics every 2 or 4 weeks, NNAL is an appropriate biomarker for evaluating the smoking cessation status. In the group of the subjects with increased NNAL levels at some point, the $\mathrm{m}^{7}$ Gua and 8-OHdG levels did not decrease in the treatment period. Smoking during the smoking cessation period may have affected these levels. By eliminating the subjects who showed increased NNAL levels at some points during the smoking cessation program, the following relationships between DNA damage markers and smoking cessation durations have become more apparent.

With regard to urinary DNA damage markers, the decreasing rates of the urinary $\mathrm{m}^{7}$ Gua and 8 -OHdG were 40.8 and $8.8 \%$ after quitting smoking for 2 weeks, and 48.1 and $2.2 \%$ after 8 weeks as compared with the beginning of the program. The decreasing rate of the $\mathrm{m}^{7} \mathrm{Gua}$ was slower than that reported previously (54\% reduction after smoking cessation for 1 week) [36]. The reason for this difference may be due to the limited number of subjects and the low $\mathrm{m}^{7}$ Gua levels at the beginning of cessation in the previous report. In this study, urinary 8OHdG levels were decreased by 2 weeks of smoking cessation. However, among the subjects who completed the smoking cessation program, the reduction rate at 8 weeks was limited. Further studies are needed to confirm the sustained effects of the lower 8-OHdG levels elicited by quitting smoking. Several studies have shown reductions of urinary 8-OHdG levels upon quitting smoking $[37,38]$. In one study of urinary 8 -OHdG levels after quitting smoking, the $8-\mathrm{OHdG}$ levels decreased by $23 \%$ at 4 and 26 weeks. There was no change in 8 -OHdG levels after 4 weeks of smoking cessation [37], and thus the oxidative stress caused by smoking could be eliminated by quitting smoking for 1 month. The urinary 8OHdG levels are widely employed as a useful biomarker for monitoring the oxidative stress status involved in cancer induction and lifestyle-related diseases. Although smoking is one of the major factors in elevated 8-OHdG levels, many other factors also increase them, such as ionizing radiation [39], environmental pollutants, lifestyle choices such as alcohol drinking, and so on [22, 40]. Better clarification of the health effects of smoking could be achieved with an assessment combination including another biomarker like $\mathrm{m}^{7} \mathrm{Gua}$, which is produced by a different mechanism than that of 8-OHdG.

In a cross-sectional study, the urinary $\mathrm{m}^{7}$ Gua levels positively correlated with cigarette smoking [41]. According to Spearman's rank correlation coefficient (Table 2) in this study, the urinary $\mathrm{m}^{7}$ Gua level was weakly associated with the cotinine and NNAL levels as the tobacco exposure markers. The results of our longitudinal epidemiological study were also in good agreement with the previous cross-sectional study [42].

\section{Conclusions}

In patients participating in a smoking cessation program, the levels of urinary DNA damage markers $\left(\mathrm{m}^{7}\right.$ Gua and 8-OHdG) decreased with the duration of smoking cessation, in the same manner as the smoking exposure markers (nicotine, cotinine and NNAL). The urinary levels of cotinine and NNAL positively correlated with the $\mathrm{m}^{7} \mathrm{Gua}$ levels. NNAL may be an appropriate exposure marker for evaluating the smoking status of patients in a smoking cessation program.

\section{Abbreviations \\ NNAL: 4-(methylnitrosamino)-1-(3-pyridyl)-1-butanol; NNK: 4- (methylnitrosamino)-1-(3-pyridyl)-1-butanone; 8-OHdG: 8-hydroxy-2'- deoxyguanosine; $\mathrm{m}^{7}$ Gua: 7-methylguanine}

\section{Acknowledgements}

We thank Dr. H. Kasai for helpful advice regarding the $8-\mathrm{OHdG}$ measurement.

\section{Authors' contributions}

YK, KK, KN and HY collected the urine samples. YK and KK analyzed nicotine, cotinine and NNAL in urine. Y-S L and $Y O$ analyzed $8-O H d G$ and $m^{7} G u a$ in urine. YK statistically analyzed the data. KK and YK designed and critically discussed the study. All authors read and approved the final manuscript.

\section{Funding}

This work was supported by Health and Labour Sciences Research Grant (JPMH19FA1006 and H28-Junkankitou-Ippan-002), and JSPS KAKENHI Grant Number JP17H01908.

\section{Availability of data and materials Not applicable.}

\section{Ethics approval and consent to participate}

The study was approved by the Ethics Committee of Medical Research, University of Occupational and Environmental Health, Japan.

Consent for publication

Not applicable.

Competing interests

The authors declare that they have no competing interests. 


\section{Author details}

${ }^{1}$ Department of Environmental Oncology, Institute of Industrial Ecological Sciences, University of Occupational and Environmental Health, Japan, 1-1 Iseigaoka, Yahatanishi-ku, Kitakyushu, Fukuoka 807-8555, Japan. ${ }^{2}$ Nagata Medical Clinic, 4-3-1 Takasu Higashi, Wakamatsu-ku, Kitakyushu, Fukuoka 808-0144, Japan. ${ }^{3}$ Department of Health Development, Institute of Industrial Ecological Sciences, University of Occupational and Environmental Health, Japan, 1-1 Iseigaoka, Yahatanishi-ku, Kitakyushu, Fukuoka 807-8555, Japan. ${ }^{4}$ Center for Stress-related Disease Control and Prevention, University of Occupational and Environmental Health, Japan, 1-1 Iseigaoka, Yahatanishi-ku, Kitakyushu, Fukuoka 807-8555, Japan.

Received: 1 July 2020 Accepted: 1 September 2020 Published online: 11 September 2020

\section{References}

1. Talhout R, Schulz T, Florek E, van Benthem J, Wester P, Opperhuizen A Hazardous compounds in tobacco smoke. Int J Environ Res Public Health. 2011:8:613-28.

2. Khariwala SS, Hatsukami D, Hecht SS. Tobacco carcinogen metabolites and DNA adducts as biomarkers in head and neck cancer: potential screening tools and prognostic indicators. Head Neck. 2012;34:441-7.

3. IARC Working Group on the Evaluation of Carcinogenic Risks to Humans. Tobacco smoke and involuntary smoking. IARC Monogr Eval Carcinog Risks Hum. 2004;83:1-1438.

4. Ministry of Health, Labour and Welfare. National Health and Nutrition Survey. 2018. https://www.mhlw.go.jp/bunya/kenkou/kenkou_eiyou_chousa. html Accessed $10 \mathrm{Jul} 2020$

5. Perkins KA, Karelitz JL, Jao NC. Optimal carbon monoxide criteria to confirm 24-hr smoking abstinence. Nicotine Tob Res. 2013;15:978-82.

6. Benowitz NL, Bernert JT, Foulds J, Hecht SS, Jacob P, Jarvis MJ, et al. Biochemical verification of tobacco use and abstinence: 2019 update. Nicotine Tob Res. 2019;22:1086-97.

7. Gariti P, Alterman Al, Ehrman R, Mulvaney FD, O'Brien CP. Detecting smoking following smoking cessation treatment. Drug Alcohol Depend. 2002;65:191-6.

8. Gupta S, Benowitz N, Jacob P, Rolf C, Gorsline J. Bioavailability and absorption kinetics of nicotine following application of a transdermal system. Br J Clin Pharmacol. 1993;36:221-7.

9. Benowitz NL, Jacob P, Fong I, Gupta S. Nicotine metabolic profile in man: comparison of cigarette smoking and transdermal nicotine. J Pharmacol Exp Ther. 1994;268:296-303.

10. Sobue S, Sekiguchi K, Kikkawa H, Akasaki M, Irie S. Comparison of nicotine pharmacokinetics in healthy Japanese male smokers following application of the transdermal nicotine patch and cigarette smoking. Biol Pharm Bull. 2006;29:1068-73.

11. Benowitz NL, Hukkanen J, Jacob P 3rd. Nicotine chemistry metabolism and kinetics. Handb Exp Pharmacol. 2010;192:29-60.

12. Bernert JT, Alexander JR, Sosnoff CS, McGuffey JE. Time course of nicotine and cotinine incorporation into samples of nonsmokers' beard hair following a single dose of nicotine polacrilex. J Anal Toxicol. 2011;35:1-7.

13. Hecht SS, Carmella SG, Chen M, Dor Koch JF, Miller AT, Murphy SE, et al. Quantitation of urinary metabolites of a tobacco-specific lung carcinogen after smoking cessation. Cancer Res. 1999;59:590-6.

14. Stepanov I, Carmella SG, Han S, Pinto A, Strasser AA, Lerman C, et al. Evidence for endogenous formation of $\mathrm{N}^{\prime}$-nitrosonornicotine in some longterm nicotine patch users. Nicotine Tob Res. 2009;11:99-105.

15. Hecht SS. Human urinary carcinogen metabolites: biomarkers for investigating tobacco and cancer. Carcinogenesis. 2002;23:907-22.

16. Hecht SS. Carcinogen derived biomarkers: applications in studies of human exposure to secondhand tobacco smoke. Tob Control. 2003;13(Suppl 1):i48-56.

17. Peterson LA. Context matters: contribution of specific DNA adducts to the genotoxic properties of the tobacco-specific nitrosamine NNK. Chem Res Toxicol. 2017:30:420-33.

18. Rinne ML, He Y, Pachkowski BF, Nakamura J, Kelley MR. N-methylpurine DNA glycosylase overexpression increases alkylation sensitivity by rapidly removing non-toxic 7-methylguanine adducts. Nucleic Acids Res. 2005;33: 2859-67.

19. Suzuki T, Katayama Y, Komatsu Y, Kamiya H. Analysis of large deletion mutations induced by abasic site analog in human cells. Genes Environ. 2018:40:1-8.
20. Rusyn I, Asakura S, Li Y, Kosyk O, Koc H, Nakamura J, et al. Effects of ethylene oxide and ethylene inhalation on DNA adducts, apurinic/ apyrimidinic sites and expression of base excision DNA repair genes in rat brain, spleen, and liver. DNA Repair (Amst). 2005;4:1099-110.

21. Crosbie PAJ, Harrison K, Shah R, Watson AJ, Agius R, Barber PV, et al. Topographical study of O6-alkylguanine DNA alkyltransferase repair activity and N7-methylguanine levels in resected lung tissue. Chem Biol Interact. 2013;204:98-104.

22. Lee HL, Hsueh YM, Chung CJ, Pu YS, Chang LW, Hsieh DPH, et al. Correlation between the urine profile of 4-(methylnitrosamino)-1-(3-pyridyl)1-butanone metabolites and N7-methylguanine in urothelial carcinoma patients. Cancer Epidemiol Biomark Prev. 2008;17:3390-5.

23. Kasai $\mathrm{H}$. Analysis of a form of oxidative DNA damage, 8-hydroxy-2'deoxyguanosine, as a marker of cellular oxidative stress during carcinogenesis. Mutat Res - Rev Mutat Res. 1997;387:147-63.

24. Kasai H, Kawai K. 8-Hydroxyguanine, an oxidative DNA and RNA modification. In: Jurga S, Erdmann VA, Barciszewski J, editors. Modified nucleic acids in biology and medicine. Cham: Springer International Publishing; 2016. p. 147-85.

25. Kasai $\mathrm{H}$. What causes human cancer? Approaches from the chemistry of DNA damage. Genes Env. 2016;38:19.

26. Loft S, Vistisen K, Ewertz M, Tjønneland A, Overvad K, Poulsen HE. Oxidative DNA damage estimated by 8-hydroxydeoxyguanosine excretion in humans: influence of smoking, gender and body mass index. Carcinogenesis. 1992; 13:2241-7.

27. Asami S, Hirano T, Yamaguchi R, Tomioka Y, Itoh H, Kasai H. Increase of a type of oxidative DNA damage, 8-hydroxyguanine, and its repair activity in human leukocytes by cigarette smoking. Cancer Res. 1996;56:2546-9.

28. Irie M, Tamae K, Iwamoto-Tanaka N, Kasai H. Occupational and lifestyle factors and urinary 8-hydroxydeoxyguanosine. Cancer Sci. 2005;96:600-6.

29. Watanabe S, Kawasaki Y, Kawai K. Salivary 8-hydroxyguanine as a lifestyle-related oxidative stress biomarker in workers. J Clin Biochem Nutr. 2020;66:57-61.

30. Kawai K, Kasai H, Li YS, Kawasaki Y, Watanabe S, Ohta M, et al. Measurement of 8-hydroxyguanine as an oxidative stress biomarker in saliva by HPLC-ECD. Genes Environ. 2018;40:2-5.

31. Cao C, Lai T, Li M, Zhou H, Lv D, Deng Z, et al. Smoking-promoted oxidative DNA damage response is highly correlated to lung carcinogenesis. Oncotarget. 2016;7:18919-26.

32. Kasai H, Svoboda P, Yamasaki S, Kawai K. Simultaneous determination of 8hydroxydeoxyguanosine, a marker of oxidative stress, and creatinine, a standardization compound, in urine. Ind Health. 2005;43:333-6.

33. Goniewicz ML, Havel CM, Peng MW, Jacob P, Dempsey D, Yu L, et al. Elimination kinetics of the tobacco-specific biomarker and lung carcinogen 4-(methylnitrosamino)-1-(3-pyridyl)-1-butanol. Cancer Epidemiol Biomark Prev. 2009:18:3421-5.

34. Derby KS, Cuthrell K, Caberto C, Carmella SG, Franke AA, Hecht SS, et al. Nicotine metabolism in three ethnic/racial groups with different risks of lung cancer. Cancer Epidemiol Biomark Prev. 2008;17:3526-35.

35. Benowitz N, Goniewicz ML, Eisner M, Lazcano-Ponce E, Zielinska-Danch W Koszowski B, et al. Urine cotinine underestimates exposure to the tobaccoderived lung carcinogen 4-(methylnitrosamino)-1-(3-pyridyl)-1-butanone in passive compared with active smokers. Cancer Epidemiol Biomark Prev. 2010:19:2795-800.

36. Ichiba M, Matsumoto A, Kondoh T, Horita M, Tomokuni K. Decreasing urinary PAH metabolites and 7-methylguanine after smoking cessation. Int Arch Occup Environ Health. 2006;79:545-9.

37. Priemé H, Loft S, Klarlund M, Grønbæk K, Tønnesen P, Poulsen HE. Effect of smoking cessation on oxidative DNA modification estimated by 8-0xo-7,8dihydro-2'-deoxyguanosine excretion. Carcinogenesis. 1998;19:347-51.

38. Morita H, Ikeda H, Haramaki N, Eguchi H, Imaizumi T. Only two-week smoking cessation improves platelet aggregability and intraplatelet redox imbalance of long-term smokers. J Am Coll Cardiol. 2005:45:589-94.

39. Li YS, Song MF, Kasai H, Kawai K. Generation and threshold level of 8-OHdG as oxidative DNA damage elicited by low dose ionizing radiation. Genes Environ. 2013;35:88-92.

40. Li YS, Kawasaki Y, Watanabe S, Ootsuyama Y, Kasai H, Kawai K. Diurnal and daytoday variation of urinary oxidative stress marker 8-hydroxy-2'deoxyguanosine. J Clin Biochem Nutr. 2020; in press.

41. Tamae K, Kawai K, Yamasaki S, Kawanami K, Ikeda M, Takahashi K, et al. Effect of age, smoking and other lifestyle factors on urinary 7methylguanine and 8-hydroxydeoxyguanosine. Cancer Sci. 2009;100:715-21. 
42. Hu CW, Hsu YW, Chen JL, Tam LM, Chao MR. Direct analysis of tobacco-specific nitrosamine NNK and its metabolite NNAL in human urine by LC-MS/MS: evidence of linkage to methylated DNA lesions. Arch Toxicol. 2014;88:291-9.

\section{Publisher's Note}

Springer Nature remains neutral with regard to jurisdictional claims in published maps and institutional affiliations.

Ready to submit your research? Choose BMC and benefit from:

- fast, convenient online submission

- thorough peer review by experienced researchers in your field

- rapid publication on acceptance

- support for research data, including large and complex data types

- gold Open Access which fosters wider collaboration and increased citations

- maximum visibility for your research: over $100 \mathrm{M}$ website views per year

At $\mathrm{BMC}$, research is always in progress.

Learn more biomedcentral.com/submissions 